\title{
Evaluating the Effects of the Nonplanarity of Nucleic Acid Bases on NMR, IR, and Vibrational Circular Dichroism Spectra: A Density Functional Theory Computational Study
}

\author{
Zuzana Vokáčová,*,† Lukáš Trantírek, ${ }^{*,+, \S}$ and Vladimír Sychrovský ${ }^{*, \dagger}$ \\ Institute of Organic Chemistry and Biochemistry, v.v.i., Academy of Sciences of the Czech Republic, \\ Flemingovo square 2, 16610 Prague 6, Czech Republic, and Biology Centre, v.v.i., Academy of Sciences of \\ the Czech Republic, Branisovska 31, 370 05, Ceske Budejovice, Czech Republic
}

Received: March 15, 2010; Revised Manuscript Received: July 30, 2010

\begin{abstract}
The pyramidalizations of N9/1 glycosidic nitrogens in DNA and RNA nucleosides, recently discovered and analyzed in their ultrahigh-resolution X-ray crystal structures (Sychrovský; et al. Nucleic Acid Res. 2009, 37, 7321.), were found to have significant effects on the structural interpretation of the ${ }^{3} J\left(\mathrm{C} 4 / 2-\mathrm{H} 1^{\prime}\right)$ and ${ }^{3} J(\mathrm{C} 8 /$ $6-\mathrm{H}^{\prime}$ ) NMR scalar couplings in purine/pyrimidine nucleosides. The calculated effects on IR and vibrational circular dichroism (VCD) spectra were only minor. The calculated structural deformations in nucleosides, depending on sugar-to-base orientation, gave rise to corrections in the phase shift of the Karplus equations for the ${ }^{3} J\left(\mathrm{C} 8 / 6-\mathrm{H} 1^{\prime}\right)$ and ${ }^{3} J\left(\mathrm{C} 4 / 2-\mathrm{H} 1^{\prime}\right)$ couplings ranging from $-26^{\circ}$ to $+25^{\circ}$ and from $-5.7^{\circ}$ to $+2.0^{\circ}$, respectively. The sign alternation of this correction in syn and anti nucleosides arises from the stereoinversion of the N9/1 glycosidic nitrogen occurring upon reorientation of the glycosidic torsion. The effect was calculated consistently in the $\mathrm{dG}, \mathrm{dA}, \mathrm{dC}, \mathrm{dT}, \mathrm{rA}$, and $\mathrm{rG}$ nucleosides. Utilization of the calculated phase-shift corrections in the design of Karplus equations for the ${ }^{3} J$ couplings was suggested, and the effects on structural interpretation of the experimental couplings were evaluated.
\end{abstract}

\section{Introduction}

High-resolution information on nucleic acid (NA) structure is usually derived either from X-ray-diffraction studies or by NMR spectroscopy. The fact that the structures and dynamics of NAs are strongly sensitive to interactions with the surrounding environment, such as water molecules, ions, or molecular crowding, ${ }^{1-10}$ makes NMR spectroscopy the exclusive tool for the structural characterization of NA under physiological conditions. ${ }^{11}$

The glycosidic torsion angle ( $\chi$ torsion) is one of the fundamental local structural descriptors of NAs. The $\chi$ torsion measures the local orientation of an NA base with respect to the sugar ribose (Figure 1). In addition, the $\chi$ torsion is correlated with the global helical structure of NA polynucleotides. ${ }^{12}$ Although there exist many NMR methods for determining the $\chi$ torsion, such as measurement of the proton-relaxation time $T_{1},{ }^{13-16}$ one-bond or long-range proton-carbon scalar couplings ( $J$ couplings), or the utilization of a lanthanide-ion probe, ${ }^{17-20}$ in practice only the NOEs (the nuclear Overhauser effect) ${ }^{21-23}$ between protons in the sugar and the base and/or the threebond proton-carbon scalar couplings are widely used. The interproton distances obtained from the sugar-to-base NOEs, $\mathrm{H}^{\prime}{ }^{\prime}-\mathrm{H} 8$ in purines and $\mathrm{H}^{\prime}-\mathrm{H} 6$ in pyrimidines, are suitable for distinguishing the anti and syn nucleosides because their respective interproton distances differ by $1.2 \AA$. However, an accuracy better than $\pm 50^{\circ}$ in $\chi$ torsions evaluated with NOEs can be hardly guaranteed because the uncertainty in determined interproton distances is large, around $\pm 0.2 \AA .{ }^{24}$ Measurement

* To whom correspondence should be addressed. E-mail: Z.V. zuzana.vokacova@uochb.cas.cz; L.T., L.Trantirek@uu.nl; V.S., vladimir. sychrovsky@uochb.cas.cz.

Institute of Organic Chemistry and Biochemistry.

* Biology Centre.

$\$$ Present address: Department of Chemistry, Utrecht University, Utrecht, The Netherlands. of the ${ }^{3} J\left(\mathrm{C} 4 / 2-\mathrm{H} 1^{\prime}\right)$ and ${ }^{3} J\left(\mathrm{C} 8 / 6-\mathrm{H} 1^{\prime}\right)$ couplings in purine/ pyrimidine nucleosides, in contrast, offers a more accurate alternative for obtaining $\chi$ torsion, providing that the correct relationship between ${ }^{3} J$ couplings and $\chi$ is known. ${ }^{24}$

Although it was Lemieux ${ }^{25}$ who first pointed out the existence of a relationship between the ${ }^{3} J\left(\mathrm{C} 2-\mathrm{H}^{\prime}\right)$ and ${ }^{3} J\left(\mathrm{C} 6-\mathrm{H} 1^{\prime}\right)$ couplings in uridine and $\chi$ torsion, the first actual parametrization of the respective Karplus equations (KE) was by Davies, using the values of ${ }^{3} J$ couplings measured in cyclouridine and cyclocytidine having structurally locked and thus a priori known values of $\chi$ torsion. $^{26}$ In 1994, Zhu et al. showed that the KEs by Davies ${ }^{26}$ could also be used in a qualitative way for guanosines in a DNA G-quadruplex. ${ }^{27}$ Two years later, Ippel et al. showed that the same KEs also hold qualitatively for adenosines. ${ }^{28}$ Using the published NMR data and their own results, Ippel et al. reparametrized and generalized the KEs for the ${ }^{3} J$ couplings across glycosidic bonds in all DNA and RNA nucleosides. ${ }^{28}$ In 2002, Trantírek et al. determined the $\chi$ torsions in the $\left[\mathrm{d}\left(\mathrm{G}_{4} \mathrm{~T}_{4} \mathrm{G}_{4}\right)\right]_{2}$ DNA G-quadruplex using Ippel's parametrization. ${ }^{29}$ Their detailed analysis revealed that the KE by Ippel can be used to discriminate syn and anti nucleosides, but it could

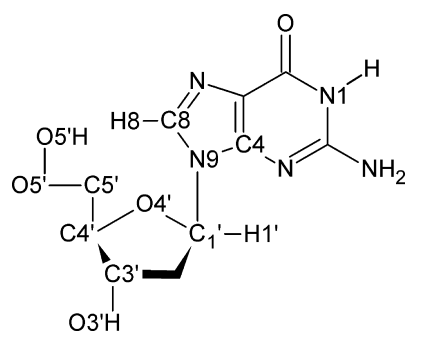

Figure 1. Schematic representation of $2^{\prime}$-deoxyguanosine. The key atoms and glycosidic torsion $\left(\chi=\mathrm{O}^{\prime}-\mathrm{Cl}^{\prime}-\mathrm{N} 9-\mathrm{C} 4\right)$ are labeled in the standard way according to IUPAC nomenclature. ${ }^{35}$ Other geometric parameters used in the text are defined as follows: $\lambda^{\prime}=\left(\mathrm{H} 1^{\prime}-\mathrm{C} 1^{\prime}-\mathrm{N} 9 /\right.$ $\left.1-\mathrm{O} 4^{\prime}-120^{\circ}\right)$ and $\kappa^{\prime}=\left(\mathrm{C} 4 / 2-\mathrm{N} 9 / 1-\mathrm{C}^{\prime}-\mathrm{C} 8 / 6-180^{\circ}\right)$. 
not provide accurate $\chi$ values in purine nucleotides. ${ }^{29}$ Trantírek et al. therefore proposed new $\mathrm{KEs}^{29}$ based on NMR data measured in the G-quadruplex. Although this parametrization provided a notable improvement for the 2 -deoxypurines, its general validity was still questioned due to the complete lack of NMR data for syn-pyrimidines. ${ }^{29}$ To address this issue, Munzarová and Sklenár performed a detailed theoretical analysis of the ${ }^{3} J\left(\mathrm{C} 4 / 2-\mathrm{H} 1^{\prime}\right)$ and ${ }^{3} J\left(\mathrm{C} 8 / 6-\mathrm{H} 1^{\prime}\right)$ dependences on $\chi$ torsion in DNA nucleosides using the DFT method. ${ }^{30,31}$ Their calculations clearly demonstrated that accurate structural interpretation of the ${ }^{3} J$ couplings requires base-specific KEs. In particular, while the ${ }^{3} J\left(\mathrm{C} 8 / 6-\mathrm{H} 1^{\prime}\right)$ differed only in the $2^{\prime}$-deoxypurines and $2^{\prime}$-deoxypyrimidines, the ${ }^{3} J\left(\mathrm{C} 4 / 2-\mathrm{H} 1^{\prime}\right)$ also exhibited different behavior in $2^{\prime}$-deoxycytidine and $2^{\prime}$-deoxythymidine. ${ }^{30,31}$ In our recent work, we showed that the sugar pucker in DNA and RNA nucleosides also has an effect on the KEs. ${ }^{32}$

Of note, the calculated $\mathrm{KEs}^{30-32}$ in fact reflected the deformations of an idealized geometry (see below) at the glycosidic nitrogen that was a prerequisite for all the empirical parametrizations. ${ }^{24,28}$ It was shown that this fact implies the necessity of correcting the phase in KEs. The phases in the theoretical $\mathrm{KEs}^{30-32}$ are therefore shifted by $7-10^{\circ}$ with respect to the phase accepted for the idealized structural model of nucleotides. Although the calculated $\mathrm{KEs}^{30-32}$ seemingly provided insight into the topic, their use still turned out to be problematic; the $\chi$ torsions calculated in syn nucleosides were underestimated, while in anti nucleosides they were overestimated in comparison with the available experimental data. ${ }^{30-32}$ The explanation for this peculiar behavior was provided only recently by our group. Systematic analysis of the crystal structures of nucleosides at ultrahigh resolution showed that NA bases are intrinsically nonplanar at N9/1. ${ }^{33}$ Importantly, our analysis revealed that glycosidic nitrogens in purine bases adopt a pyramidal configuration that undergoes stereoinversion upon reorientation of the $\chi$ torsion from the syn to the anti region. ${ }^{33}$ These new data strongly suggest that all previously established KEs were biased, as they either were parametrized under the assumption of rigid nucleobases (the empirical KEs) or reflected the actual nonplanarity of nucleobases insufficiently (the theoretical KEs).

Because the geometry deformations in nucleosides depend specifically on glycosidic-bond orientation, ${ }^{33}$ the KEs for the ${ }^{3} J$ couplings require nontrivial (nonconstant) phase corrections. In this study, we revised the currently available KEs and used the DFT method to calculate the effects of the structural deformations on the phase of the KEs for the ${ }^{3} J\left(\mathrm{C} 4 / 2-\mathrm{H}^{\prime}\right)$ and ${ }^{3} J\left(\mathrm{C} 8 / 6-\mathrm{H}^{\prime}\right)$ scalar couplings as well as the IR and vibrational circular dichroism (VCD) spectra. Previously, these geometry deformations have been reflected in NMR parameters only as constant phase shifts in the KEs..$^{30-32}$ In this study, we show that the previously adopted theoretical approach was only the first step for improving the KEs because their phase shifts are modulated significantly by the pyramidalization of glycosidic nitrogens, which depends on $\chi$ torsion in a nontrivial way. The new facts thus address the general validity of constant phase shifts in KEs for the cases where such local structural variations invalidate the idealized structural model.

\section{Theory: Structural Interpretation of NMR ${ }^{3} J$ Scalar Couplings}

The dependence of a three-bond ${ }^{3} J$ coupling constant on the assigned torsion angle ( $\theta$ torsion) in the form of truncated Fourier series:

$$
{ }^{3} J(\theta)=\sum_{m=0}^{2} C_{m} \cos (m \theta)=C_{0}+C_{1} \cos (\theta)+C_{2} \cos (2 \theta)
$$

was first suggested by Karplus. ${ }^{34}$ The relation of the $C_{\mathrm{m}}$ coefficients to the magnitude of ${ }^{3} J$ coupling is the following: $C_{0}$ is the mean value of the ${ }^{3} J$ constant over the $0-360^{\circ}$ interval of $\theta$ torsion, $C_{2}-C_{1}$ is equal to the maximal difference of ${ }^{3} \mathrm{~J}$ coupling from the mean value $C_{0}$, and $C_{1}$ is equal to one-half the ${ }^{3} J$ difference between the syn-periplanar and anti-periplanar orientations of $\theta$ torsion. The revised eq 1

$$
{ }^{3} J(\theta)=A \cos ^{2}(\theta)+B \cos (\theta)+C
$$

is known as a Karplus equation for ${ }^{3} J$ couplings. The coefficients $A, B$, and $C$ are linked to $C_{0}, C_{1}$, and $C_{2}$ as follows: $A=2 C_{2}$, $B=C_{1}$, and $C=C_{0}-C_{2}$.

The chain of four atoms $\mathrm{X} 1-\mathrm{X} 2-\mathrm{X} 3-\mathrm{X} 4$ defining the $\theta$ torsion is called the spin-spin coupling pathway of the ${ }^{3} J(\mathrm{X} 1-\mathrm{X} 4)$ coupling. Note that the $\chi$ torsion in nucleosides (Figure 1) does not correspond to the spin-spin pathway of a measurable ${ }^{3} J$ coupling because the relaxation properties of oxygen ${ }^{17} \mathrm{O}$ are unfavorable for such NMR measurements. Instead, the ${ }^{3} J\left(\mathrm{C} 8 / \mathrm{C} 6-\mathrm{H} 1^{\prime}\right)$ and ${ }^{3} J\left(\mathrm{C} 4 / 2-\mathrm{H} 1^{\prime}\right)$ couplings are used for determining the $\chi$ torsion in purine/pyrimidine nucleosides. Their spin-spin pathway as determined by NMR must be therefore be shifted once interpreted in terms of $\chi$ torsion. This shift corresponds to a difference between the measured spin - spin pathway $\theta$ and $\chi$ torsion.

The phase shift of the ${ }^{3} J\left(\mathrm{C} 8 / 6-\mathrm{H} 1^{\prime}\right)$ and ${ }^{3} J\left(\mathrm{C} 4 / 2-\mathrm{H}^{\prime}\right)$ couplings used for determining the $\chi$ torsion can be decomposed into the following contributions:

$$
\theta=\chi+\Delta \chi+\varphi
$$

where $\Delta \chi$ is the constant phase shift corresponding to the idealized geometry of a glycosidic bond, with a tetrahedral arrangement of the four atoms linked to $\mathrm{C}^{\prime}$ and a planar arrangement of the $\mathrm{C1}^{\prime}, \mathrm{C} 4, \mathrm{C} 8$, and $\mathrm{N} 9$ atoms (Figure 1). This geometry is here referred to as the idealized hybridization geometry of the glycosidic bond or simply the idealized geometry. The $\Delta \chi$ equals $k \pi / 3, k=0,1, \ldots, 5$ according to the IUPAC. ${ }^{35}$ The $\varphi$ shift introduced in this study is a correction in $\Delta \chi$ due to deformations of the idealized geometry. The decomposition of the $\theta$ torsion in eq 3 matches current models for interpreting the ${ }^{3} J\left(\mathrm{C} 8 / 6-\mathrm{H}^{\prime}\right)$ and $^{3} J\left(\mathrm{C} 4 / 2-\mathrm{H} 1^{\prime}\right)$ couplings $^{24,28,29}$ when $\Delta \chi$ is an appropriate constant chosen in accord with the IUPAC and $\varphi$ is zero for all values of $\chi$ torsion.

The spin-spin pathways of all ${ }^{3} J$ couplings investigated in this study include the $\mathrm{H} 1^{\prime}-\mathrm{C}^{\prime}-\mathrm{N} 9 / 1$ link, and the remaining terminal atom was either the carbon $\mathrm{C} 4 / 2$ or $\mathrm{C} 8 / 6$ in purine/ pyrimidine nucleosides (Figure 1). We therefore used the same indexing for the respective $\Delta \chi$ shifts matching the ideal structural model in purine/pyrimidine nucleosides: $\Delta \chi_{\mathrm{C} 4 / 2}=120^{\circ}$ and $\Delta \chi_{\mathrm{C} 8 / 6}=-60^{\circ}$. Similarly, we introduced the $\varphi_{\mathrm{C} 4 / 2}$ and $\varphi_{\mathrm{C} 8 / 6}$ shifts.

The $\varphi$ shift arises due to the deformation of the idealized hybridization geometry at carbon $\mathrm{C}^{\prime}$ and nitrogen $\mathrm{N} 9 / 1$. These two respective contributions to $\varphi$ shift are equal to the $\lambda^{\prime}$ and $\kappa^{\prime}$ torsion angles (Figure 1; $\kappa^{\prime}$ was described previously in ref $33)$. Because the spin-spin pathway of ${ }^{3} J\left(\mathrm{C} 4 / 2-\mathrm{H} 1^{\prime}\right)$ coupling coincides with $\chi$ torsion at the site of the nucleobase (the 

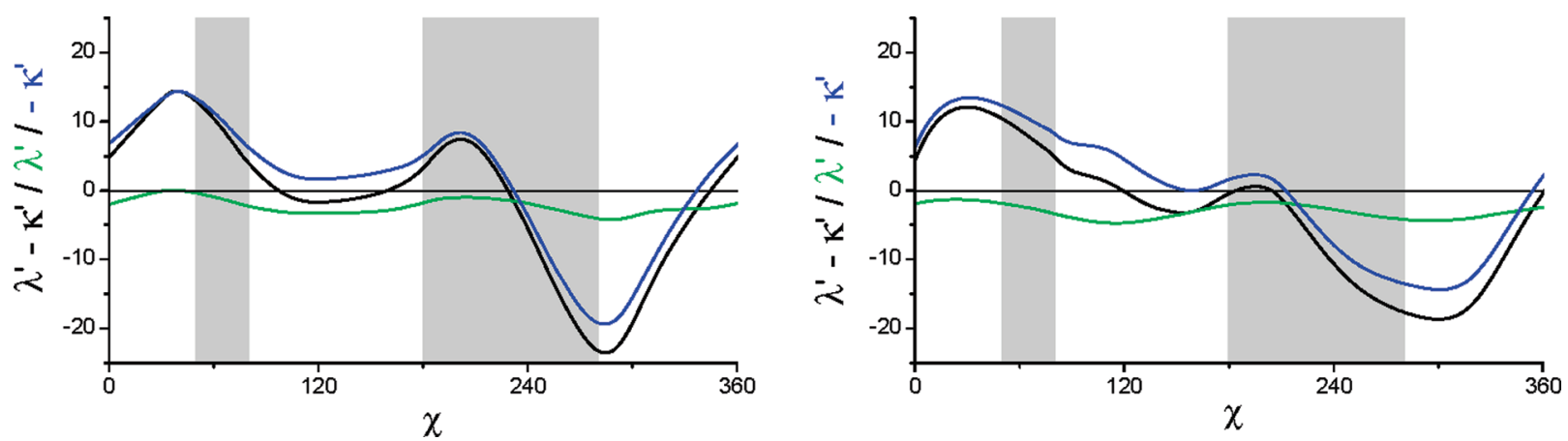

Figure 2. Dependence of the $\lambda^{\prime}$ (green) and $-\kappa^{\prime}$ (blue) torsion angle and their sum $\lambda^{\prime}-\kappa^{\prime}$ (black) on the glycosidic torsion $\chi$ calculated for dG with $\mathrm{C} 2^{\prime}$-endo (left) and $\mathrm{C}^{\prime}$-endo (right) sugar pucker. The $\lambda^{\prime}$ and $\lambda^{\prime}-\kappa^{\prime}$ values correspond to the $\varphi_{\mathrm{C} 4}$ and $\varphi_{\mathrm{C} 8}$ phase shift corrections, respectively. The structurally important syn $\left(50^{\circ}<\chi<80^{\circ}\right)$ and anti $\left(180^{\circ}<\chi<280^{\circ}\right)$ regions are shaded. All geometric parameters are in degrees.

$\mathrm{C} 1^{\prime}-\mathrm{N} 9 / 1-\mathrm{C} 4$ link, Figure 1), the $\kappa^{\prime}$ contribution to the $\varphi_{\mathrm{C} 4 / 2}$ shift is zero. For the spin-spin pathway of the ${ }^{3} J\left(\mathrm{C} 8 / 6-\mathrm{H} 1^{\prime}\right)$ coupling, the $\varphi_{\mathrm{C} 8 / 6}$ shift consists of both $\lambda^{\prime}$ and $\kappa^{\prime}$ contributions. We will show that the $\kappa^{\prime}$ represents major component of the $\varphi_{\mathrm{C} 8 / 6}$ shift.

\section{Methods}

Geometry optimization and determination of the scalar NMR spin-spin coupling constants of 2'-deoxyadenosine (dA), $2^{\prime}$ deoxycytidine $(\mathrm{dC}), 2^{\prime}$-deoxyguanosine $(\mathrm{dG})$, guanosine $(\mathrm{rG})$, and 2 -deoxythymidine (dT) molecules were described previously. ${ }^{32,36}$ Molecular geometries of these molecules and adenosine molecule (rA) obtained in this study were optimized with the B3LYP functional and the $6-31 G^{* *}$ basis set. The sugar-phosphate backbone fragment was kept frozen to the B-DNA conformation $\left(\beta, \mathrm{C}^{\prime}-\mathrm{C}^{\prime}-\mathrm{O}^{\prime}-\mathrm{O}^{\prime} \mathrm{H}=176^{\circ} ; \gamma\right.$, $\mathrm{C} 3^{\prime}-\mathrm{C}^{\prime}-\mathrm{C}^{\prime}-\mathrm{O}^{\prime}=48^{\circ}$; Figure 1$)$ or the A-RNA conformation $\left(\beta, \mathrm{C} 4^{\prime}-\mathrm{C}^{\prime}-\mathrm{O}^{\prime}-\mathrm{O}^{\prime} \mathrm{H}=173^{\circ} ; \gamma, \mathrm{C}^{\prime}-\mathrm{C}^{\prime}-\mathrm{C}^{\prime}-\mathrm{O} 5^{\prime}\right.$ $\left.=54^{\circ} ; \varepsilon, \mathrm{O}^{\prime} \mathrm{H}-\mathrm{C} 3^{\prime}-\mathrm{C}^{\prime}-\mathrm{C} 5^{\prime}=210^{\circ}\right)$ during these optimizations. The $\chi$ torsion was varied stepwise with steps smaller than $40^{\circ}$, while all remaining geometric parameters in the nucleosides except the fixed $\beta$ and $\gamma$ torsions were reoptimized (see ref 32). The dependences calculated previously ${ }^{32}$ and in this work, including spline fits of the calculated data points, can be found in the Supporting Information. This adiabatic relaxation of geometry was carried out for all nucleosides having both $\mathrm{C}^{2}$ endo and $\mathrm{C}^{\prime}$-endo sugar pucker ( $\mathrm{C}^{\prime}$ and $\mathrm{C} 3^{\prime}$ sugars). We note that the overall sugar conformation preserved its pucker and did not interconvert when the $\chi$ torsion was varied. The adiabatic constraint used in the geometry optimization of all nucleosides corresponded to the $\chi$ torsion. ${ }^{32,36}$

The scalar NMR spin-spin coupling constants ${ }^{37,38}$ were computed using the coupled perturbed density functional theory (CP-DFT) method ${ }^{39,40}$ with the B3LYP functional and the IgloIII basis set ${ }^{41}$ by including all four terms: diamagnetic spin-orbit (DSO), paramagnetic spin-orbit (PSO), Fermi contact (FC), and spin dipolar (SD). The ${ }^{n} J(\mathrm{X}-\mathrm{Y})$ scalar coupling constants were calculated between atoms $\mathrm{X}$ and $\mathrm{Y}\left({ }^{1} \mathrm{H},{ }^{13} \mathrm{C}\right)$, where $n$ is the number of covalent bonds separating the linked atoms.

The vibrational IR and VCD spectra were calculated using the B3LYP functional and the $6-31 \mathrm{G}^{* *}$ basis set. All calculations were done with the Gaussian 03 software package. ${ }^{42}$

\section{Results and Discussion}

1. Dependence of the Geometry Deformations at N9/1 and C1' Sites on $\chi$ Torsion. The assumption of idealized geometry at nitrogen $\mathrm{N} 9 / 1$ and carbon $\mathrm{C}^{\prime}$ ' has been generally accepted in all structural models for empirically parametrized KEs. ${ }^{24} \mathrm{We}$ remind the reader that these models all presume a planar nucleobase with zero pyramidalization at N9/1 and a tetrahedral geometry at $\mathrm{C}^{\prime}$, so that both the $\kappa^{\prime}$ and $\lambda^{\prime}$ torsions are equal to $0^{\circ}$.

The dependences of $\lambda^{\prime}$ and $\kappa^{\prime}$ on $\chi$ torsion calculated for the $\mathrm{dG}$ nucleosides (Figure 2) as well as for all other investigated nucleosides (Supporting Information) showed that the prerequisite of an idealized geometry is acceptable only for a few sugar-to-base orientations (Figure $2,100^{\circ}<\chi<180^{\circ}, \chi \approx 350^{\circ}$ ) which are moreover insignificantly populated in NAs. ${ }^{12,43}$ The geometry deformations arising due to N9/1 pyramidalization $\left(\kappa^{\prime}\right)$ were very similar in all investigated nucleosides and were more pronounced in the anti compared to the syn region of $\chi$ torsion. The only exception is the case of rA where both pyramidalizations were equivalent. The geometry deformations at $\mathrm{C1}^{\prime}\left(\lambda^{\prime}\right)$ were similar and practically equivalent in all deoxynucleosides (Supporting Information). In the ribo-nucleosides, the calculated $\lambda^{\prime}$ dependences were also very similar but overall smaller as compared to the deoxy-nucleosides. The absolute values for ribo- and deoxy-nucleosides differed on average by $1.5^{\circ}$. The deformation at $\mathrm{C}^{\prime}$ in ribo-nucleosides is from this point of view practically negligible and closer to the idealized structural model. The sign of the complete $\lambda^{\prime}-\kappa^{\prime}$ dependence changed with a revolution of $\chi$ torsion due to the stereoinversion of pyramidalization at N9/1. The complete dependences were only slightly modulated by the $\lambda^{\prime}$ dependences because their magnitudes were notably smaller than those arising from the $\mathrm{N} 9 / 1$ pyramidalization for all nucleosides.

The $\lambda^{\prime}$ and $-\kappa^{\prime}$ dependences calculated for the $\mathrm{dG}$ nucleosides with $\mathrm{C} 2^{\prime}$-endo $\left(\mathrm{C}^{\prime} \mathrm{dG}\right)$ and $\mathrm{C}^{\prime}$ '-endo $\left(\mathrm{C}^{\prime}{ }^{\prime} \mathrm{dG}\right)$ sugar pucker were different (Figure 2). Although this different puckering of the ribose sugar did not change the overall trend of the calculated dependences, as we also concluded in our previous study, ${ }^{32}$ it had an effect on their curvatures and on the magnitudes of their absolute maxima. The effect of sugar pucker on the calculated $\lambda^{\prime}$ and $\kappa^{\prime}$ dependences can most probably be explained by the different flexibilities of the $\mathrm{C}^{\prime}$ ' and $\mathrm{C}^{\prime}$ ' sugars and their different relaxation upon change of sugar-to-base orientation. Nevertheless, the effect of sugar pucker seems to be important in the structural interplay between sugar and nucleobase because the absolute maximum of the $\lambda^{\prime}-\kappa^{\prime}$ dependence in all analyzed C3' nucleosides was systematically smaller than that in $\mathrm{C}^{\prime}{ }^{\prime}$ ones except for the $\mathrm{C}^{\prime}$ and $\mathrm{C}^{\prime}{ }^{\prime} \mathrm{rA}$ where the absolute maxima had comparable values. (Figure S1, Supporting Information).

2. Effects of the Geometry Deformations at the N9/1 and $\mathrm{C1}^{\prime}$ Sites on Structural Interpretation of the ${ }^{3} \boldsymbol{J}$ Couplings. The existence of a non-zero phase-shift correction $\varphi$ (eq 3 ) for the ${ }^{3} J$ couplings across the glycosidic bond can be deduced from 

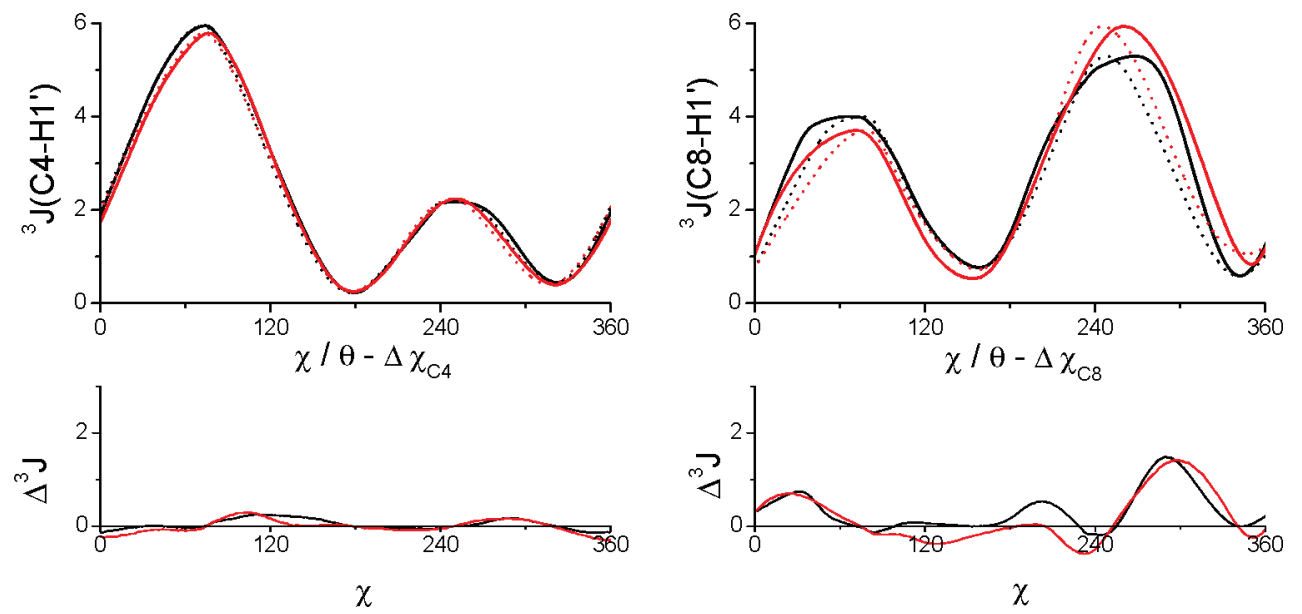

Figure 3. Top: dependence of the ${ }^{3} J\left(\mathrm{C} 4-\mathrm{H} 1^{\prime}\right)$ and ${ }^{3} J\left(\mathrm{C} 8-\mathrm{H} 1^{\prime}\right)$ coupling constants (Hz) on sugar-to-base orientation calculated for dG assigned to the glycosidic torsion $\chi$ (full line) and to the glycosidic torsion including the phase shift $\theta-\Delta \chi=\chi+\varphi$ (dotted line) in degrees. The dependences were calculated for the $\mathrm{C}^{\prime}$-endo (black line) and $\mathrm{C}^{\prime}$-endo (red line) sugar pucker. Bottom: calculated differences between the two assignments in Hz. The curves were obtained as spline fits of the calculated data (see Supporting Information).

their calculated dependences, assigned primarily to the $\chi$ torsion measured directly in nucleosides and secondarily to the $\theta-$ $\Delta \chi$ torsion angle measured as the exact spin-spin pathway of ${ }^{3} J$ coupling corrected by the $\Delta \chi$ phase shift reflecting only the idealized structural model (Figure 3, Supporting Information). Where the two calculated dependences coincide, the $\varphi_{\mathrm{C} 4 / 2}$ and $\varphi_{\mathrm{C} 8 / 6}$ shift must be zero because the $\theta-\Delta \chi$ torsion in fact equals $\chi+\varphi$ (eq 3 ).

The difference in ${ }^{3} J$ coupling calculated with the two assignments (Figure 3) was first pointed out by Munzarová et al. ${ }^{31}$ and also in our previous study. ${ }^{32}$ The ${ }^{3} J$ dependence calculated with the $\theta-\Delta \chi$ assignment is perfectly symmetric and expected periodic behavior that can be conveniently fitted as a linear combination of cosines (eq 2). Note that this assignment cannot be used for obtaining $\chi$ torsion directly; this requires knowledge of the $\varphi$ dependence on $\chi$ torsion. The ${ }^{3} J$ dependence calculated with the $\chi$ assignment is deformed but it directly provides correct values of $\chi$ torsion. Fitting the deformed ${ }^{3} J$ dependence with a function in the form of the linear combination of cosines would lead to an invalid KE (see below). Thus, the determination of $\chi$ torsion from the calculated ${ }^{3} \mathrm{~J}$ dependences assigned to $\theta-\Delta \chi$ clearly requires the $\lambda^{\prime}-\kappa^{\prime}$ correction that arises mainly due to the N9/1 pyramidalization.

Exact periodicity of the KEs was postulated in their empirical models. ${ }^{24}$ However, the calculated dependences of ${ }^{3} J$ couplings indicated that once the idealized model is structurally perturbed, the exact periodicity of a $\mathrm{KE}$ is not conserved. As a result, the two cases, i.e., the empirical fitting and the fitting of calculated data, must be treated separately. In the first case it is not possible to include the effect of N9/1 pyramidalization without a prior knowledge of its dependence on $\chi$ torsion. In the second case, the fitting of calculated ${ }^{3} J$ dependence on $\chi$ would be in conflict with the periodicity of the KE dictated by the idealized structural model. Although the calculated ${ }^{3} J$ dependence on $\theta-\Delta \chi$ could be fitted in the usual way, as it is periodic, its direct use (without $\varphi$ correction) cannot provide correct $\chi$ torsion values.

A way of overcoming this dilemma has been suggested in the previous theoretical studies. The phase $\Delta \chi$ was not treated as a constant during the fitting procedure but was optimized in the same way as the $A, B$, and $C$ coefficients (eq 2). ${ }^{31,32}$ Note that the explicit dependence of the phase factor on $\chi$ torsion was not considered and the fitted value of $\Delta \chi$ was therefore only shifted from the value reflecting the idealized structural
TABLE 1: Minimal and Maximal Values of $\varphi_{\mathrm{C} 4 / 2}\left(\lambda^{\prime}\right)$ and $\varphi_{\mathrm{C} 8 / 6}\left(\lambda^{\prime}-\kappa^{\prime}\right)(\mathrm{deg})$ Geometric Parameters Calculated in the Syn $\left(0-180^{\circ}\right)$ and Anti $\left(180-360^{\circ}\right)$ Regions of $\chi$ Torsion for All Purine (dA, rA, dG, rG) and Pyrimidine (dC, dT) Nucleosides

\begin{tabular}{|c|c|c|c|c|c|}
\hline & \multirow[b]{2}{*}{$\chi(\operatorname{deg})$} & \multicolumn{2}{|c|}{$\mathrm{C} 2$ '-endo } & \multicolumn{2}{|c|}{ C3'-endo } \\
\hline & & $\min$ & $\max$ & $\min$ & $\max$ \\
\hline \multirow{3}{*}{ purine } & & $\varphi_{\mathrm{C} 4 / 2}$ & & & \\
\hline & $0-180$ & -3.85 & 1.95 & -4.87 & 1.21 \\
\hline & $180-360$ & -4.85 & 1.07 & -4.54 & 0.13 \\
\hline \multirow[t]{2}{*}{ pyrimidine } & $0-180$ & -3.73 & 0.20 & -5.66 & -0.93 \\
\hline & $180-360$ & -3.57 & -0.30 & -5.65 & -1.15 \\
\hline \multirow{3}{*}{ purine } & & $\varphi_{\mathrm{C} 8 / 6}$ & & & \\
\hline & $0-180$ & -7.21 & 17.57 & -5.62 & 24.63 \\
\hline & $180-360$ & -26.05 & 16.82 & -20.96 & 3.54 \\
\hline \multirow[t]{2}{*}{ pyrimidine } & $0-180$ & -4.28 & 12.64 & -9.89 & 15.44 \\
\hline & $180-360$ & -25.58 & 6.73 & -21.17 & 6.39 \\
\hline
\end{tabular}

model. However, we would anticipate that this approach could only partially remedy the invalid prerequisite of an idealized model, as the phase in structurally valid KEs not only depends on $\chi$ torsion but also alters the sign due to the N9/1 stereoinversion.

The two assignments, $\chi$ and $\theta-\Delta \chi$, of the ${ }^{3} J\left(\mathrm{C} 4 / 2-\mathrm{H}^{\prime}\right)$ coupling were virtually the same as the geometry deformations at $\mathrm{Cl}^{\prime}$ were small and the $\mathrm{N} 9 / 1$ pyramidalization did not contribute to the $\varphi_{\mathrm{C} 4 / 2}$ shift (see the $\lambda^{\prime}$ dependence in Figure 2 ). The $\lambda^{\prime}$ dependences in all nucleosides were essentially the same and the calculated $\varphi_{\mathrm{C} 4 / 2}$ shifts ranged from $-5.7^{\circ}$ to $+2.0^{\circ}$ (Table 1, Supporting Information). One might therefore assume that the $\varphi_{\mathrm{C} 4 / 2}$ could in principle be fitted as a constant. However, the $\varphi_{\mathrm{C} 4 / 2}$ shifts obtained previously ranged from $8.3^{\circ}$ to $11.7^{\circ} .31,32$ This fact points to the deficiency of the approach, and one may anticipate that equivalent numerical treatment of the expansion coefficients and phase cannot guarantee obtaining a correct fit of the KE.

The reparametrization of the KE particularly concerns the ${ }^{3} J\left(\mathrm{C} 8 / 6-\mathrm{H} 1^{\prime}\right)$ coupling because the $\varphi_{\mathrm{C} 8 / 6}$ shift incorporates the geometry deformations at both $\mathrm{C}^{\prime}$ and N9/1 (Figure 2). The large absolute magnitude of the $\varphi_{\mathrm{C} 8 / 6}$ shift together with its alternating sign complicates structural interpretation of this coupling. The maximal absolute error in $\chi$ torsion when the $\varphi_{\mathrm{C} 8 / 6}$ shift is neglected can reach up to $26^{\circ}$ (Table 1 ). The uncertainty, or error delta $\chi$, of $26^{\circ}$ corresponds to a delta 


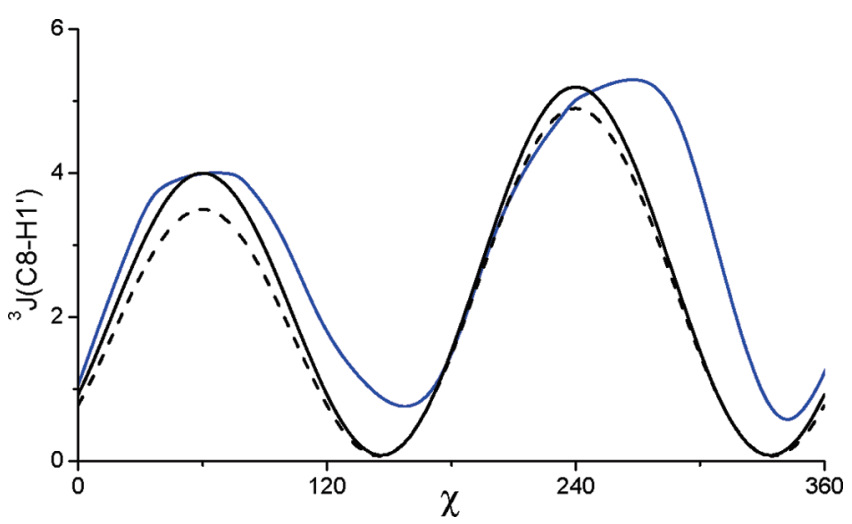

Figure 4. Dependence of ${ }^{3} J\left(\mathrm{C} 8-\mathrm{H}^{\prime}\right)$ coupling $(\mathrm{Hz})$ on $\chi$ torsion (deg) calculated in the $\mathrm{C} 2{ }^{\prime} \mathrm{dG}$ (blue) and the empirical KE by Ippel ${ }^{28}$ (black) and Trantírek ${ }^{29}$ (black dashed).

${ }^{3} J\left(\mathrm{C} 8-\mathrm{H} 1^{\prime}\right)$ of $2.2 \mathrm{~Hz}$ (this value was estimated in the calculated dependence in Figure 4 for $\chi$ equal to $290^{\circ}$ ). Such an error exceeds the experimental error of this coupling, typically ranging from 0.1 to $0.2 \mathrm{~Hz}$, by $5-10$-fold. ${ }^{30}$ Furthermore, neglecting the effect of N9/1 stereoinversion (i.e., ignoring the sign of $\varphi_{\mathrm{C} 8 / 6}$ ) can, in the worst-case scenario, result in an error in the relative positioning of the two bases of up to $51^{\circ}$ (Table 1). Taken together, the $\varphi_{\mathrm{C} 8 / 6}$ correction in the KEs for ${ }^{3} J\left(\mathrm{C} 8 / 6-\mathrm{H} 1^{\prime}\right)$ is essential for their accurate parametrization.

3. Utilization of the Calculated Phase Corrections in the Structural Interpretation of the ${ }^{3} \boldsymbol{J}$ Couplings. We propose three ways to employ the calculated $\varphi$ corrections for more accurate structural interpretation of the ${ }^{3} J$ couplings.

The first, a graphical approach, is based on the direct use of the ${ }^{3} J / \chi$ calculated data points or the curves obtained as spline fits of the theoretical data for the assignment to $\chi$ torsion (Figure 3, Supporting Information).

The second approach involves explicit parametrization of the $\mathrm{KE}$ with the calculated ${ }^{3} J$ coupling assigned directly to the $\chi$ torsion. Any mathematical function relevant for fitting such a $\mathrm{KE}$ is, however, aperiodic because $\varphi$ depends on $\chi$ torsion nontrivially. As a result, the substitution of the function $\varphi(\chi)$ into the argument of the cosine (eq 2) is problematic. However, this approach represents the only way to obtain an explicit form of the KE with the correct aperiodic behavior. Although such a $\mathrm{KE}$ does not facilitate the routine evaluation of $\chi$, it can be easily encoded and conveniently used for calculating structure or for the backward evaluation of scalar couplings in the process of structure refinement. For this case, we propose a form of $\varphi(\chi)$ as a linear combination of sine functions (Supporting Information).

The third approach is based on the subsequent application of the $\varphi(\chi)$ correction after the $\chi$ torsion is determined with a usual $\mathrm{KE}$ constructed according to the idealized structural model, e.g., with the KE by Ippel $^{28}$ or Trantirek ${ }^{29}$ (Figure 4). In this case, the predetermined value of $\chi$ torsion is subsequently corrected with the value of the $\varphi$ shift corresponding to this $\chi$ value. For example, the $\varphi$ values can be estimated in Figure 2. Comparison of the three KEs in Figure 4 further highlights the problematic intervals of $\chi$ torsion requiring such correction. We consider this third approach the most convenient for practical applications.

5. Effects of N9 Pyramidalization on IR and VCD Spectra. The vibrational IR and VCD spectra calculated for the $\mathrm{C} 2^{\prime} \mathrm{dG}$ nucleoside with a nearly planar nucleobase at the glycosidic nitrogen $\left(\chi=160^{\circ}\right)$ were compared with the spectra calculated in the two $\mathrm{dG}$ nucleosides having the maximal pyramidalization at N9 with opposite out-of-plane deviations

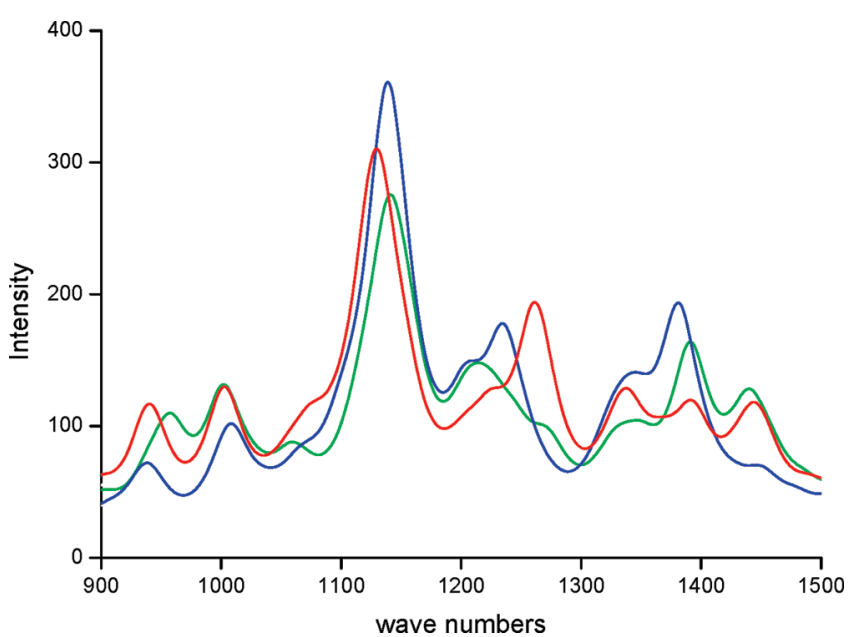

Figure 5. Dependence of the IR intensity on the vibration frequency in $\mathrm{cm}^{-1}$ calculated for the $\mathrm{C}^{\prime}$-endo $\mathrm{dG}$ nucleoside with the glycosidic torsion angle equal to $160^{\circ}$ (blue), $40^{\circ}$ (green), and $290^{\circ}$ (red).

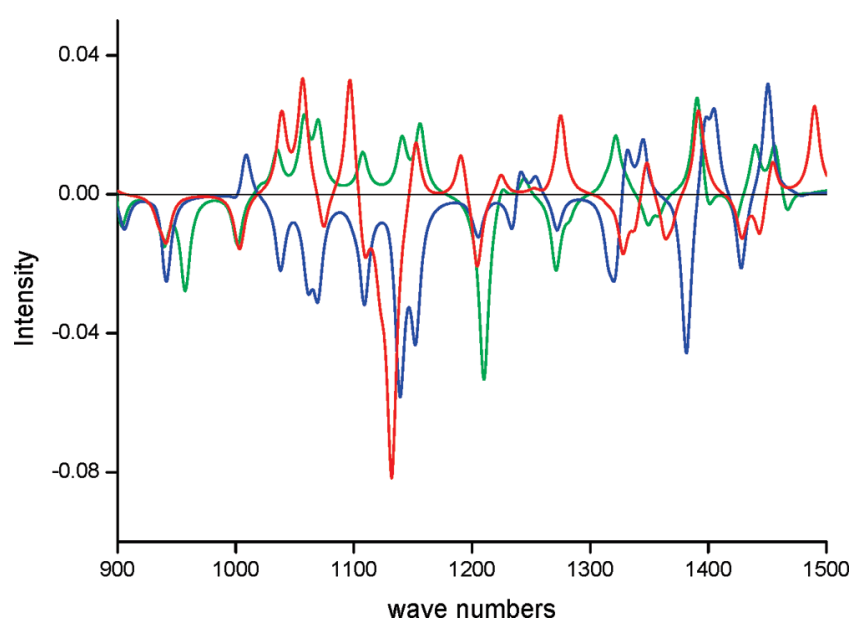

Figure 6. VCD spectra calculated for the $\mathrm{C} 2$ '-endo $\mathrm{dG}$ nucleoside with the glycosidic torsion angle equal to $160^{\circ}$ (blue), $40^{\circ}$ (green), and $290^{\circ}$ (red).

$\left(\chi=40^{\circ}\right.$ and $\chi=290^{\circ}$ ) (Figure 5 and 6; for complete spectra see the Supporting Information).

According to the assignment of IR bands in NAs, the 900-1500 $\mathrm{cm}^{-1}$ range contains the characteristic base-sugar vibrations $\left(1500-1250 \mathrm{~cm}^{-1}\right)$ and sugar vibrations $(800-1000$ $\left.\mathrm{cm}^{-1}\right) .{ }^{44}$ It should be mentioned that the normal vibration modes were highly delocalized and thus the calculated peaks could not be assigned solely to certain well-resolved molecular motions. Nevertheless, several specific changes in the calculated spectra were observed.

The intensities of two bands in the $930-1010 \mathrm{~cm}^{-1}$ range of the IR spectra and a band at $1450 \mathrm{~cm}^{-1}$ calculated for the $\mathrm{dG}$ with minimal pyramidalization were smaller than that calculated in the two $\mathrm{dG}$ nucleosides with nonplanar nucleobases $(\chi=$ $40^{\circ}$ and $\chi=290^{\circ}$ ). In the case of dominant bands at $1050 \mathrm{~cm}^{-1}$ and bands at 1330 and $1390 \mathrm{~cm}^{-1}$ the situation was the opposite. The calculated band at $1335 \mathrm{~cm}^{-1}$ assigned to the base-sugar vibrations sensitive to the glycosidic bond rotation ${ }^{44}$ was virtually the same in all three $\mathrm{dG}$ conformers. The differences in the IR spectra calculated for the two dG nucleosides with opposite out-of-plane deviations of N9 were larger than those between the IR spectrum for $\mathrm{dG}$ with maximal and minimal pyramidalization (the 940 or $1080 \mathrm{~cm}^{-1}$ bands). Although the three calculated IR spectra showed different trends, which can 
be assigned to different pyramidalizations of the glycosidic nitrogen, in all probability their practical observation would be limited. Any interpretation of IR spectra measured in NAs with the calculated assignments would be difficult, as none of the calculated trends would be distinguishable in the complicated mixture of many similar IR bands originating from base-sugar and sugar-phosphate vibrations. ${ }^{44}$ However, under special conditions when a certain kind of notable pyramidalization at the glycosidic nitrogen is repeated in an NA polynucleotide, the calculated trends for out-of-plane vibrations at N9 may be amplified and become distinguishable from other vibrations.

In the calculated VCD spectra, we searched mainly for the bands reflecting different chiralities at N9 in the three dG nucleosides. The $900-1500 \mathrm{~cm}^{-1}$ range contained many bands of relatively low intensity in comparison with the remaining parts of the calculated VCD spectra. Only the $1260-1270 \mathrm{~cm}^{-1}$ bands calculated in the three $\mathrm{dG}$ nucleosides with different pyramidalizations, which can be assigned to the in-plane deformations of the nucleobase, reflected the N9 chirality. An opposite sign of this band was calculated for the opposite pyramidalization at N9 and a decrease in the band amplitude was calculated for the planar nucleobase at N9. The bands in the $1000-1100 \mathrm{~cm}^{-1}$ range calculated for the $\mathrm{dG}$ nucleosides with a large pyramidalization at N9 or a planar nucleobase had opposite signs. In other parts of the VCD spectra, outside of the $900-1500 \mathrm{~cm}^{-1}$ region, we found sharp and large bands seemingly characteristic of the $\mathrm{dG}$ nucleoside with a planar nucleobase.

Taken together, the calculated trends in the IR and VCD spectra were only loosely related to the degree of $\mathrm{N} 9$ pyramidalization in $\mathrm{dG}$ nucleosides. It can be therefore anticipated that the pyramidalization would most probably be barely detectable in the IR or VCD spectra.

\section{Conclusions}

The calculated deformations of geometry at $\mathrm{N} 9 / 1$ and $\mathrm{Cl}^{\prime}$ sites in the $\mathrm{dA}, \mathrm{rA}, \mathrm{dC}, \mathrm{dG}, \mathrm{dT}$, and $\mathrm{rG}$ nucleosides depending on their sugar-to-base orientations have profound effects on structural interpretation of the NMR spin-spin couplings across the glycosidic bond. The effects on IR and VCD spectra are less significant.

Both the degree and orientation of pyramidalization at the glycosidic nitrogen depends significantly on the orientation of the glycosidic torsion $\chi$. The maximal degree of pyramidalization was calculated consistently in the anti nucleosides. In general, the $\mathrm{C}^{\prime}$ nucleosides had greater pyramidalization than the C3'nucleosides. The C3' rA nucleoside represents the only exception; its maximal pyramidalization in the syn region is comparable to the overall absolute maximum calculated for all anti nucleosides.

The calculated structural deviations from the idealized nucleoside model (with a planar nucleobase) significantly affected the value of the phase shift in the Karplus equations for the ${ }^{3} J\left(\mathrm{C} 8 / 6-\mathrm{H} 1^{\prime}\right)$ and ${ }^{3} J\left(\mathrm{C} 4 / 2-\mathrm{H} 1^{\prime}\right)$ couplings. The corresponding corrections ranged from $-26^{\circ}$ to $+25^{\circ}$ and from $-5.7^{\circ}$ to $+2.0^{\circ}$ for the ${ }^{3} J\left(\mathrm{C} 8 / 6-\mathrm{H} 1^{\prime}\right)$ and ${ }^{3} J\left(\mathrm{C} 4 / 2-\mathrm{H} 1^{\prime}\right)$ couplings, respectively.

The maximal error in glycosidic torsion $\chi$ determined from the ${ }^{3} J$ couplings due to incorrect assignment arising from neglecting the nonplanarity of nucleobases and geometry deformation at $\mathrm{C1}^{\prime}$ can reach $26^{\circ}$. Such an error in the determination of $\chi$ torsion corresponds to a difference in ${ }^{3} J\left(\mathrm{C} 8-\mathrm{H} 1^{\prime}\right)$ couplings equal to $2.2 \mathrm{~Hz}$. Of note, the error due to neglecting the nonplanarity of nucleobases and geometry deformation at $\mathrm{Cl}^{\prime}$ is $5-10$-fold larger than typical experimental error in the determination of ${ }^{3} \mathrm{~J}\left(\mathrm{C} 8-\mathrm{H} 1^{\prime}\right)$. Among the three approaches suggested for more accurate determination of $\chi$ torsion, the subsequent application of calculated corrections to the $\chi$ torsion(s) determined by empirical $\mathrm{KE}$ is the most applicable.

The nonplanarity of nucleobases can be probably detected by IR or VCD spectroscopy only in special circumstances wherein the NA polynucleotides have repetitive structural motifs ensuring amplification of the assigned and theoretically calculated bands. Otherwise, they would be probably mixed with other peaks independent of this structural effect and therefore be indistinguishable.

The theoretical calculations in this work provide a link between local structural effects and molecular-spectroscopy parameters, which can be used for more accurate determination of the $\chi$ torsion from the three-bond proton-carbon scalar coupling across the glycosidic bond. The so-far neglected pyramidalization and stereoinversion of the glycosidic nitrogen can be ranked as similarly important for the structural studies of nucleic acids as the effects of solvent or the effect of molecular motion and vibrations. This study therefore pointed out the general importance of such local structural effects, which are inevitably linked with the variation of global molecular structure, for the more accurate interpretation of spectroscopic parameters.

Supporting Information Available: Figures showing the dependence of geometrical parameters on the sugar to base orientation, the dependence of $J$ couplings on the torsion angle, the dependence of the IR intensity on vibrational frequency, the VCD spectra, and the calculated dependence of the $\varphi_{\mathrm{C} 8}$ corrections on the glycosidic torsion angle.

Tables of $J$ couplings and geometric paramters. This material is available free of charge via the Internet at http://pubs.acs.org.

\section{References and Notes}

(1) Brukner, I.; Susic, S.; Dlakic, M.; Savic, A.; Pongor, S. J. Mol. Biol. 1994, 236, 26.

(2) Han, W. H.; Dlakic, M.; Zhu, Y. W. J.; Lindsay, S. M.; Harrington, R. E. Proc. Natl. Acad. Sci. U.S.A. 1997, 94, 10565.

(3) Hardin, C. C.; Watson, T.; Corregan, M.; Bailey, C. Biochemistry 1992, 31, 833 .

(4) Miyoshi, D.; Matsumura, S.; Li, W.; Sugimoto, N. Nucleosides Nucleotides Nucleic Acids 2003, 22, 203.

(5) Miyoshi, D.; Nakao, A.; Sugimoto, N. Nucleic Acids Res. 2003, 31,1156

(6) Woodson, S. A. Curr. Opin. Chem. Biol. 2005, 9, 104.

(7) Koculi, E.; Hyeon, C.; Thirumalai, D.; Woodson, S. A. J. Am. Chem. Soc. 2007, 129, 2676.

(8) Moghaddam, S.; Caliskan, G.; Chauhan, S.; Hyeon, C.; Briber, R. M.; Thirumalai, D.; Woodson, S. A. J. Mol. Biol. 2009, 393, 753.

(9) Heddi, B.; Foloppe, N.; Bouchemal, N.; Hantz, E.; Hartmann, B. J. Am. Chem. Soc. 2006, $128,9170$.

(10) Heddi, B.; Foloppe, N.; Hantz, E.; Hartmann, B. J. Mol. Biol. 2007, 368,1403 .

(11) Hansel, R.; Foldynova-Trantirkova, S.; Lohr, F.; Buck, J.; Bongartz, E.; Bamberg, E.; Schwalbe, H.; Dotsch, V.; Trantirek, L. J. Am. Chem. Soc. 2009, 131, 15761.

(12) Schneider, B.; Morávek, Z.; Berman, H. M. Nucleic Acids Res. 2004, 32, 1666.

(13) Imoto, T.; Akasaka, K.; Hatano, H. Chem. Lett. 1974, 73.

(14) Akasaka, K.; Imoto, T.; Shibata, S.; Hatano, H. J. Magn. Reson. 1975, $18,328$.

(15) Ludemann, H. D.; Westhof, E.; Roder, O. Eur. J. Biochem. 1974, $49,143$.

(16) Chachaty, C.; Zemb, T.; Langlet, G.; Son, T. D.; Buc, H.; Morange, M. Eur. J. Biochem. 1976, 62, 45.

(17) Barry, C. D.; North, A. C. T.; Glasel, J. A.; Williams, R. J. P.; Xavier, A. V. Nature 1971, 232, 236.

(18) Birdsall, B.; Birdsall, N. J. M.; Feeney, J.; Thornton, J. J. Am. Chem. Soc. 1975, 97, 2845. 
(19) Geraldes, C.; Williams, R. J. P. Eur. J. Biochem. 1978, 85, 463.

(20) Davies, D. B.; Rajani, P.; Sadikot, H. J. Chem. Soc., Perkin Trans. 2 1985, 279.

(21) Noggle, J. H.; Schirmer, R. E. The nuclear overhauser effect: chemical applications; Academic Press: New York, 1971.

(22) Gueron, M.; Chachaty, C.; Son, T. D. Ann. N. Y. Acad. Sci. 1973, $222,307$.

(23) Chachaty, C.; Perly, B.; Forchioni, A.; Langlet, G. Biopolymers 1980, 19, 1211.

(24) Wijmenga, S. S.; van Buuren, B. N. M. Prog. NMR Spectrosc. 1998, $32,287$.

(25) Lemieux, R. U. Pure Appl. Chem. 1971, 25.

(26) Davies, D. B.; Rajani, P.; Maccoss, M.; Danyluk, S. S. Magn. Reson. Chem. 1985, 23, 72.

(27) Zhu, G.; Live, D.; Bax, A. J. Am. Chem. Soc. 1994, 116, 8370.

(28) Ippel, J. H.; Wijmenga, S. S.; de Jong, R.; Heus, H. A.; Hilbers, C. W.; de Vroom, E.; van der Marel, G. A.; van Boom, J. H. Magn. Reson. Chem. 1996, 34, S156.

(29) Trantírek, L.; Štefl, R.; Masse, J. E.; Feigon, J.; Sklenář, V. J. Biomol. NMR 2002, 23, 1.

(30) Munzarová, M. L.; Sklenář, V. J. Am. Chem. Soc. 2002, 124, 10666.

(31) Munzarová, M. L.; Sklenář, V. J. Am. Chem. Soc. 2003, 125, 3649.

(32) Vokáčová, Z.; Bickelhaupt, F. M.; Šponer, J.; Sychrovský, V. J. Phys. Chem. A 2009, 113, 8379.

(33) Sychrovský, V.; Foldynová-Trantírková, S.; Špačková, N.; Robeyns,

K.; Meervelt, L. V.; Blankenfeldt, W.; Vokáčová, Z.; Šponer, J.; Trantírek,

L. Nucleic Acid Res. 2009, 37, 7321.

(34) Karplus, M. J. Am. Chem. Soc. 1963, 85, 2870.

(35) Markley, J. L.; Bax, A.; Arata, Y.; Hilbers, C. W.; Kaptein, R.;

Sykes, B. D.; Wright, P. E.; Wüthrich, K. J. Biomol. NMR 1998, 12, 1.

(36) Sychrovský, V.; Muller, N.; Schneider, B.; Smrecki, V.; Špirko,

V.; Šponer, J.; Trantírek, L. J. Am. Chem. Soc. 2005, 127, 14663.
(37) Kaupp, M.; Buhl, M.; Malkin, V. Calculation of NMR and EPR Parameters. Theory and Applications; Willey-VCH Verlag: Weinheim, 2004.

(38) Helgaker, T.; Jaszunski, M.; Ruud, K. Chem. Rev. 1999, 99, 293.

(39) Sychrovský, V.; Grafenstein, J.; Cremer, D. J. Chem. Phys. 2000, 113,3530 .

(40) Helgaker, T.; Watson, M.; Handy, N. C. J. Chem. Phys. 2000, 113, 9402 .

(41) Kutzelnigg, W.; Fleischer, U.; Schindler, M. NMR - Basis Principles and Progress; Springer: Heidelberg, 1990.

(42) Frisch, M. J.; Trucks, G. W.; Schlegel, H. B.; Scuseria, G. E.; Robb, M. A.; Cheeseman, J. R.; Montgomery, J. A., Jr.; Vreven, T.; Kudin, K. N.; Burant, J. C.; Millam, J. M.; Iyengar, S. S.; Tomasi, J.; Barone, V.; Mennucci, B.; Cossi, M.; Scalmani, G.; Rega, N.; Petersson, G. A.; Nakatsuji, H.; Hada, M.; Ehara, M.; Toyota, K.; Fukuda, R.; Hasegawa, J.; Ishida, M.; Nakajima, T.; Honda, Y.; Kitao, O.; Nakai, H.; Klene, M.; Li, X.; Knox, J. E.; Hratchian, H. P.; Cross, J. B.; Bakken, V.; Adamo, C.; Jaramillo, J.; Gomperts, R.; Stratmann, R. E.; Yazyev, O.; Austin, A. J.; Cammi, R.; Pomelli, C.; Ochterski, J. W.; Ayala, P. Y.; Morokuma, K.; Voth, G. A.; Salvador, P.; Dannenberg, J. J.; Zakrzewski, V. G.; Dapprich, S.; Daniels, A. D.; Strain, M. C.; Farkas, O.; Malick, D. K.; Rabuck, A. D.; Raghavachari, K.; Foresman, J. B.; Ortiz, J. V.; Cui, Q.; Baboul, A. G.; Clifford, S.; Cioslowski, J.; Stefanov, B. B.; Liu, G.; Liashenko, A.; Piskorz, P.; Komaromi, I.; Martin, R. L.; Fox, D. J.; Keith, T.; Al-Laham, M. A.; Peng, C. Y.; Nanayakkara, A.; Challacombe, M.; Gill, P. M. W.; Johnson, B.; Chen, W.; Wong, M. W.; Gonzalez, C.; Pople, J. A. Gaussian 03, Revision C.02; Gaussian, Inc.: Wallingford, CT, 2004.

(43) Schneider, B.; Neidle, S.; Berman, H. M. Biopolymers 1997, 42, 113.

(44) Banyay, M.; Sarkar, M.; Graslund, A. Biophys. Chem. 2003, 104, 477.

JP102329T 